\title{
Can a high-flow nasal cannula substitute for noninvasive positive pressure ventilation in post-extubation respiratory failure?
}

Je Hyeong Kim

Division of Pulmonary, Sleep and Critical Care Medicine, Department of Internal Medicine, Korea University Ansan Hospital, Ansan, Korea
Received: November 25, 2015 Accepted: December 5, 2015

\section{Correspondence to}

Je Hyeong Kim, M.D.

Division of Pulmonary, Sleep and Critical Care Medicine,

Department of Internal Medicine, Korea University Ansan Hospital, 123 Jeokgeum-ro, Danwon-gu,

Ansan 15355, Korea

Tel: +82-31-412-5950

Fax: +82-31-413-5950

E-mail: chepraxis@korea.ac.kr

\section{See Article on Page 82-88}

Administration of supplemental oxygen is the first-line therapy for hypoxemic patients. Supplemental oxygen therapy is one of the most commonly used medical interventions, and is indicated when hypoxemia is suspected by history or physical examination or is documented by laboratory data. Oxygen may be delivered using low- or highflow devices. Low-flow devices, such as a nasal oxygen catheter, nasal cannula, or simple oxygen mask, deliver varying levels of inspiratory fraction of oxygen $\left(\mathrm{F}_{\mathrm{IO}_{2}}\right)$, depending on the patient's breathing pattern, peak inspiratory flow rate, tidal volume, and inspiratory time. Conventional high-flow devices, such as a Venturi mask or air-entrainment nebulizer, provide a more constant $\mathrm{F}_{\mathrm{IO}_{2}}$ than the low-flow devices, through steady entrainment of room air using the Bernoulli effect. However, at high patient inspiratory flow rates, entrained room air dilutes the oxygen and lowers $\mathrm{F}_{\mathrm{IO}_{2}}$.

A high-flow nasal cannula (HFNC) is a relatively new high-flow device being used for adults with hypoxemia. This system provides much higher and more predictable gas flow rates and $\mathrm{F}_{\mathrm{IO}_{2}}$ than conventional high-flow devices. The ap- paratus consists of an air/oxygen blender, an active heated humidifier, a single heated circuit, and a nasal cannula. At the air/oxygen blender, $\mathrm{F}_{\mathrm{IO}_{2}}$ is set from 0.21 to 1.0 in a flow of up to $60 \mathrm{~L} / \mathrm{min}$. These higher flow rates match the patients' inspiratory flow rates, may reduce anatomical dead space, and increase carbon dioxide $\left(\mathrm{CO}_{2}\right)$ washout and create a positive end-expiratory pressure (PEEP) effect [1,2]. The gas is heated and humidified with the active humidifier and delivered through the heated circuit. HFNC is more comfortable than continuous positive airway pressure and noninvasive positive pressure ventilation(NIV).

HFNC was first used and has been studied most extensively for neonatal and pediatric patients. Recently, its use for critically ill adult patients has been increasing dramatically. However, the current literature on the use of HFNC for adults includes heterogeneous patient populations and clinical diagnoses, and has yielded inconsistent reports. Previous studies have drawn attention to how HFNC can benefit adults, due to its ability to deliver a desired $\mathrm{F}_{\mathrm{IO}_{2}}$. Potential mechanisms of clinical benefits during HFNC use are as follows [3]: (1) the small, loose-fitting nasal prongs enhance comfort [4-6]; (2) 
the heat and humidification facilitate secretion removal and prevent desiccation and epithelial injury by increasing the water content of mucus $[7,8]$, and reduce the work of breathing by decreasing the metabolic cost of breathing $[1,9]$; (3) the high nasal flow rate reduces inspiratory entrainment of room air and deliver more reliable $\mathrm{F}_{\mathrm{IO}_{2}}$ [10-12]; (4) the washout of the upper airway dead space improves the efficiency of ventilation [13-15] and enhances oxygen delivery; and (5) the PEEP counterbalances auto-PEEP and decreases the work of breathing [11,16-21]. Studies have increasingly focused on the potential clinical applications and benefits of HFNC, which include enhanced oxygenation in hypoxemic respiratory failure due to pneumonia [5,15] and cardiogenic pulmonary ede$\mathrm{ma}$ [22], and decreased respiratory rates in idiopathic pulmonary fibrosis patients [16]. Postoperatively, HFNC can improve thoracoabdominal synchrony in cardiothoracic and vascular surgery patients [23], and increase end-expiratory lung volume [24] and lower escalation of therapy [25] in patients with cardiac surgery. It can also improve oxygenation and respiratory mechanics in do-not-intubate patients [26]. However, most studies addressing these applications have been of low quality with anecdotal case reports, case series, and some preliminary controlled trials, limiting the ability to draw conclusions or make recommendations. Frat et al. [27] recently reported encouraging results of a randomized multicenter trial in which HFNC significantly improved 90-day mortality versus standard oxygen and NIV in an acute hypoxemic respiratory failure, but further physiological and randomized controlled studies are needed to confirm the precise clinical advantages of HFNC.

In this issue of Korean Journal of Internal Medicine, Yoo et al. [28] reported a single-center study of a historic retrospective cohort analysis that was designed to assess the clinical efficacy of HFNC compared with NIV in patients with post-extubation respiratory failure (PERF). Among the 73 PERF patients with hypoxemia and/or hypercapnia, 39 patients were managed with NIV and 34 with HFNC. Avoidance of reintubation, duration of Intensive Care Unit (ICU) and hospital stay, ICU and hospital mortality, and incidence of ICU-acquired pneumonia associated with PERF were compared between the two strategies. The results revealed that the reintubation avoidance rate did not differ between the NIV and HFNC groups (66.7\% and $79.4 \%, p=0.223)$. The length of hospital stay,
ICU-acquired pneumonia-associated PERF, and ICU and hospital mortalities were also similar $(p>0.05)$. Subgroup analyses of patients with hypercapnia, avoidance of reintubation, and ICU and hospital mortalities also revealed no significant differences ( $p>0.05)$.

Reintubation due to PERF is associated with increased duration of ICU and hospital stay and mortality [29,30]. Patients recently extubated are prone to oxygen desaturation and frequently require high-flow oxygen therapy, and HFNC can be useful for these patients. According to previous studies about the clinical effects of HFNC in post-extubation patients, HFNC demonstrated similar effects to a high-flow face mask [6], and resulted in better oxygenation and comfort, fewer desaturation and interface displacements, and a lower reintubation rate than a Venturi mask [31]. Although a retrospective analysis, the study [28] in this issue may be the first to have directly compared HFNC with NIV in PERF patients. In other studies, escalation to NIV was used as an important clinical parameter of failure of high-flow devices, not a comparator.

The study by Yoo et al. [28] presents an important issue to be considered: can HFNC substitute for NIV in PERF patients? The results of similar effectiveness between HFNC and NIV suggest the possibility that HFNC can substitute for NIV in these patients. PERF is a comprehensive entity that encompasses hypoxemic and hypercapnic respiratory failure. In patients with acute hypoxemic respiratory failure, HFNC has been found to be effective [32] and superior to NIV in the prevention of intubation in patients with $\mathrm{PaO}_{2} / \mathrm{F}_{\mathrm{IO}_{2}} \leq 200 \mathrm{mmHg}$ and 90 day mortality [27]. However, for hypercapnic respiratory failure, NIV has been established as a primary modality. Evidence for a role of HFNC in hypercapnic respiratory therapy is limited and controversial [33,34]. In managing PERF with NIV, because of poor mask tolerance, NIV is frequently inapplicable in some patients $[35,36]$. This problem frequently interferes with clinicians' active use of NIV and clinicians seek other measures that can substitute for NIV. However, the practical difficulties in NIV application cannot justify the substitution of NIV by HFNC or skipping NIV prior to intubation in PERF patients. The possibility for substitution of NIV by HFNC should be carefully evaluated with appropriate measures. Because of its retrospective design and small study size, Yoo et al. [28] could not obtain sound results on this is- 
sue. The clinical practice of NIV cannot be controlled appropriately, and application of NIV should be considered before reintubation of failed patients with HFNC. These factors could have been responsible for the finding that NIV was ineffective even in hypercapnic PERF patients. Appropriate randomized trials are needed to address the possibility of substituting NIV with HFNC: before appropriate evidence is available, substitution of NIV by HFNC or skipping NIV application before reintubation cannot be justified.

HFNC has several advantages over conventional oxygen delivery systems, resulting in better physiological effects. Under the expectation of potential clinical effects, it has been applied in a variety of patients with diverse underlying diseases. However, concrete clinical evidence is still very limited. The clinical benefits of HFNC in specific populations, long-term effects, and optimal use of HFNC in relation to other modalities should be confirmed through future clinical studies.

\section{Conflict of interest}

No potential conflict of interest relevant to this article was reported.

\section{REFERENCES}

1. Dysart K, Miller TL, Wolfson MR, Shaffer TH. Research in high flow therapy: mechanisms of action. Respir Med 2009;103:1400-1405.

2. Ricard JD. High flow nasal oxygen in acute respiratory failure. Minerva Anestesiol 2012;78:836-841.

3. Spoletini G, Alotaibi M, Blasi F, Hill NS. Heated humidified high-flow nasal oxygen in adults: mechanisms of action and clinical implications. Chest 2015;148:253-261.

4. Rittayamai N, Tscheikuna J, Rujiwit P. High-flow nasal cannula versus conventional oxygen therapy after endotracheal extubation: a randomized crossover physiologic study. Respir Care 2014;59:485-490.

5. Roca O, Riera J, Torres F, Masclans JR. High-flow oxygen therapy in acute respiratory failure. Respir Care 2010;55:408-413.

6. Tiruvoipati R, Lewis D, Haji K, Botha J. High-flow nasal oxygen vs high-flow face mask: a randomized crossover trial in extubated patients. J Crit Care 2010;25:463-468.

7. Hasani A, Chapman TH, McCool D, Smith RE, Dilworth
JP, Agnew JE. Domiciliary humidification improves lung mucociliary clearance in patients with bronchiectasis. Chron Respir Dis 2008;5:81-86.

8. Williams R, Rankin N, Smith T, Galler D, Seakins P. Relationship between the humidity and temperature of inspired gas and the function of the airway mucosa. Crit Care Med 1996;24:1920-1929.

9. Richards GN, Cistulli PA, Ungar RG, Berthon-Jones M, Sullivan CE. Mouth leak with nasal continuous positive airway pressure increases nasal airway resistance. Am J Respir Crit Care Med 1996;154:182-186.

10. Ritchie JE, Williams AB, Gerard C, Hockey H. Evaluation of a humidified nasal high-flow oxygen system, using oxygraphy, capnography and measurement of upper airway pressures. Anaesth Intensive Care 2011;39:11031110.

11. Sim MA, Dean P, Kinsella J, Black R, Carter R, Hughes M. Performance of oxygen delivery devices when the breathing pattern of respiratory failure is simulated. Anaesthesia 2008;63:938-940.

12. Wagstaff TA, Soni N. Performance of six types of oxygen delivery devices at varying respiratory rates. Anaesthesia 2007;62:492-503.

13. Lenglet H, Sztrymf B, Leroy C, Brun P, Dreyfuss D, Ricard JD. Humidified high flow nasal oxygen during respiratory failure in the emergency department: feasibility and efficacy. Respir Care 2012;57:1873-1878.

14. Sztrymf B, Messika J, Bertrand F, et al. Beneficial effects of humidified high flow nasal oxygen in critical care patients: a prospective pilot study. Intensive Care Med 2011;37:1780-1786.

15. Sztrymf B, Messika J, Mayot T, Lenglet H, Dreyfuss D, Ricard JD. Impact of high-flow nasal cannula oxygen therapy on intensive care unit patients with acute respiratory failure: a prospective observational study. J Crit Care 2012;27:324.e9-324.e13.

16. Braunlich J, Beyer D, Mai D, Hammerschmidt S, Seyfarth HJ, Wirtz H. Effects of nasal high flow on ventilation in volunteers, COPD and idiopathic pulmonary fibrosis patients. Respiration 2013;85:319-325.

17. Groves N, Tobin A. High flow nasal oxygen generates positive airway pressure in adult volunteers. Aust Crit Care 2007;20:126-131.

18. Hasan RA, Habib RH. Effects of flow rate and airleak at the nares and mouth opening on positive distending pressure delivery using commercially available high- 
flow nasal cannula systems: a lung model study. Pediatr Crit Care Med 2011;12:e29-e33.

19. Kubicka ZJ, Limauro J, Darnall RA. Heated, humidified high-flow nasal cannula therapy: yet another way to deliver continuous positive airway pressure? Pediatrics 2008;121:82-88.

20. Saslow JG, Aghai ZH, Nakhla TA, et al. Work of breathing using high-flow nasal cannula in preterm infants. J Perinatol 2006;26:476-480.

21. Spence KL, Murphy D, Kilian C, McGonigle R, Kilani RA. High-flow nasal cannula as a device to provide continuous positive airway pressure in infants. J Perinatol 2007;27:772-775.

22. Frat JP, Brugiere B, Ragot $S$, et al. Sequential application of oxygen therapy via high-flow nasal cannula and noninvasive ventilation in acute respiratory failure: an observational pilot study. Respir Care 2015;60:170-178.

23. Itagaki T, Okuda N, Tsunano Y, et al. Effect of high-flow nasal cannula on thoraco-abdominal synchrony in adult critically ill patients. Respir Care 2014;59:70-74.

24. Corley A, Caruana LR, Barnett AG, Tronstad O, Fraser JF. Oxygen delivery through high-flow nasal cannulae increase end-expiratory lung volume and reduce respiratory rate in post-cardiac surgical patients. Br J Anaesth 2011;107:998-1004.

25. Parke R, McGuinness S, Dixon R, Jull A. Open-label, phase II study of routine high-flow nasal oxygen therapy in cardiac surgical patients. Br J Anaesth 2013;111:925931.

26. Epstein AS, Hartridge-Lambert SK, Ramaker JS, Voigt LP, Portlock CS. Humidified high-flow nasal oxygen utilization in patients with cancer at Memorial Sloan-Kettering Cancer Center. J Palliat Med 2011;14:835-839.

27. Frat JP, Thille AW, Mercat A, et al. High-flow oxygen through nasal cannula in acute hypoxemic respiratory failure. N Engl J Med 2015;372:2185-2196.

28. Yoo JW, Synn A, Huh JW, Hong SB, Koh Y, Lim CM. Clinical efficacy of high-flow nasal cannula compared to noninvasive ventilation in patients with post-extubation respiratory failure. Korean J Intern Med 2016;31:82-88.

29. Esteban A, Anzueto A, Frutos F, et al. Characteristics and outcomes in adult patients receiving mechanical ventilation: a 28-day international study. JAMA 2002;287:345355 .

30. Torres A, Gatell JM, Aznar E, et al. Re-intubation increases the risk of nosocomial pneumonia in patients needing mechanical ventilation. Am J Respir Crit Care Med 1995;152:137-141.

31. Maggiore SM, Idone FA, Vaschetto R, et al. Nasal highflow versus Venturi mask oxygen therapy after extubation: effects on oxygenation, comfort, and clinical outcome. Am J Respir Crit Care Med 2014;190:282-288.

32. Nishimura M. High-flow nasal cannula oxygen therapy in adults. J Intensive Care 2015;3:15.

33. Millar J, Lutton S, O'Connor P. The use of high-flow nasal oxygen therapy in the management of hypercarbic respiratory failure. Ther Adv Respir Dis 2014;8:63-64.

34. Nilius G, Franke KJ, Domanski U, Ruhle KH, Kirkness JP, Schneider H. Effects of nasal insufflation on arterial gas exchange and breathing pattern in patients with chronic obstructive pulmonary disease and hypercapnic respiratory failure. Adv Exp Med Biol 2013;755:27-34.

35. Nicolini A, Ferrera L, Santo M, Ferrari-Bravo M, Del Forno M, Sclifo F. Noninvasive ventilation for hypercapnic exacerbation of chronic obstructive pulmonary disease: factors related to noninvasive ventilation failure. Pol Arch Med Wewn 2014;124:525-531.

36. Ozyilmaz E, Ugurlu AO, Nava S. Timing of noninvasive ventilation failure: causes, risk factors, and potential remedies. BMC Pulm Med 2014;14:19. 